\title{
The Value of Interaction in the Acquisition of a Sign Language
}

\author{
O valor da interação na aquisição de uma língua \\ de sinais
}

Elidéa Lúcia Almeida Bernardino*

Universidade Federal de Minas Gerais

Belo Horizonte - Minas Gerais / Brasil

\begin{abstract}
The acquisition of a sign language as a first language is a subject that is also of interest to researchers from many fields of study. This acquisition is significant for both deaf children of deaf parents as well as those of hearing parents, who consequently have late access to a language like Brazilian Sign language (Libras). The present study describes a test conducted with a pair of deaf twins who have hearing parents and who had their first contact with Libras at 5 years of age. However, upon being tested less than three years later, the twins showed a performance in Libras that was comparable to a deaf child of deaf parents. Although inconclusive, this study seeks to show the value of a continuous interlocutor, together with a genuine communicative interaction beginning from childhood, as commonly occurs with deaf twins, in the acquisition of a sign language.
\end{abstract}

KEYWORDS: first language acquisition; late language acquisition; sign language; deaf twins; Libras.

RESUMO: A aquisição de uma língua de sinais como primeira língua é um assunto que interessa a pesquisadores de diversas áreas, tanto no que respeita à aquisição por crianças surdas que possuem pais surdos, quanto àquelas que têm pais ouvintes e, portanto, normalmente têm acesso tardio a uma língua como a Libras. Este estudo descreve um teste realizado com surdos gêmeos, que têm pais ouvintes e tiveram o primeiro contato com a Libras aos cinco anos. No entanto, ao serem testados, menos de três anos depois, apresentaram um desempenho na Libras comparável ao de uma criança surda que tem pais surdos. Embora não conclusivo, este estudo busca mostrar a importância de um interlocutor constante, com uma interação comunicativa genuína desde muito cedo - como a que ocorre entre surdos gêmeos -, na aquisição de uma língua de sinais.

PALAVRAS-CHAVE: aquisição de primeira língua; aquisição tardia de linguagem; língua de sinais; surdos gêmeos; Libras.

\footnotetext{
$\overline{\text { *elideabernardino@gmail.com }}$
} 


\section{Introduction}

It is well-known that deaf children, when exposed to a rich sign language model, can understand, process, and develop language skills with similar timing and patterns as that produced by hearing children under similar conditions (Emmorey, 2002; Lillo-Martin, 1999; Meier \& Newport, 1990). It is also known that deaf children who are only exposed to a spoken language that they cannot understand and process are unable to present a typical development in terms of either timing or patterns of language acquisition (Morford \& Mayberry, 2000; Mayberry, 1994). Is there anything apart from exposure to a comprehensible language model that could allow deaf children in the latter situation to improve their language performance? What if they had numerous opportunities for interaction in sign language, a modality they have full access to, even though their interlocutor does not provide a good model of a complete language? One such case would be deaf twins who are essentially creating their own sign language communication system but who have a constant interactional partner. Could this compensate for the lack of a model or make their performance appear typical once they are exposed to a model?

A pilot study was carried out comparing the performance of deaf children of deaf parents (DCDP), who had contact with a good language model from birth; deaf twins of hearing parents (TW1 and TW2), who had no contact with a sign language model until 5:2 years of age; and two other non-sibling deaf children (HP1 and HP2), who had no contact with a sign language model until 4:0 and 5:11 years of age, respectively. All children, except DCDP, began attending a school for the deaf at around 5:0 years of age and were tested at around 7:5 years of age.

The hypothesis pursued in this study is that even poor or weak signed or gestural input can help children construct their language, setting up parameters for their communication, given that they have a constant interactional partner. This situation should be possible in the presence of a partner who shares the same limited "homemade" language code, despite the absence of a proficiency model. If this hypothesis is correct, both twins should present a better performance in their sign language skills (in this case, Brazilian Sign Language - Libras) than HP1 and HP2, even though the other language variables across the four subjects are similar. In fact, the prediction is that TW1 and TW2 will be able to perform at a level that is close to DCDP, even though DCDP had had contact with a good sign language model since birth. 


\section{Language development in the presence of a model}

Under similar conditions, deaf children who have access to a language develop normally and in the same way as hearing children. Emmorey (2002) cites various studies showing that just as hearing babies babble before producing their first words, deaf babies also babble with their hands before producing their first signs. Emmorey suggests that this development of manual babbling is related to the meaning these deaf babies discover in the early hand movements that they are able to produce. Although all babies produce at least some hand shapes that resemble signs in sign languages, only babies exposed to sign languages at an early age obtain external feedback that shows them that these movements carry meaning, in turn leading to a continued development of this manual babbling, whereas babies with no sign language input do not follow this same pattern.

Deaf children of deaf parents (DCDP) usually show typical language development, because they are exposed to a sign language from birth and interact regularly with people who are fluent in that language. They show consistent advantages over deaf children of hearing parents (DCHP) in many areas: DCDP reach higher levels of formal education, show superior reading and writing skills in English, have larger English vocabularies, achieve higher academic achievement scores, and commonly show better performance in sign language skills (Hoffmeister, 2000; Padden and Ramsey, 2000; Newport \& Meier, 1985).

In summary, deaf children who have had contact with a good language model from an early age (e.g., DCDP) develop normal language skills both in terms of timing and in patterns of acquisition. Let us now turn to deaf children who do not have this type of language exposure.

\section{Language ACQUISITION in the absence of a model}

Most DCHP do not have access to a consistent language from birth, mainly due to their hearing impairment. Because over $90 \%$ of deaf children are born to hearing parents who do not know a sign language (Emmorey, 2002; Goldin-Meadow \& Mylander, 1984), those children may have no effective language exposure in infancy and early childhood. Contrary to DCDP, who are exposed to a sign language from birth, most DCHP have their first exposure to a language like Libras when they enter school, at around 6 years of age. Meier (1991) claims that, in the absence of linguistic 
stimuli, children invent their own gestural ${ }^{1}$ communication systems. GoldinMeadow and Mylander (GM\&M, 1984) studied the development of 10 DCHP whose parents decided to educate their children using only speech. From 13 months to four years of age, they showed no significant progress in English. At an early age, the children started creating isolated gestures, such as pointing and using other signals that indicated the object or event to which they were referring. After some time, they started to combine those gestures to form very simple sentences with a typical ordering of patient-action. The authors found that those deaf children's gestures were not a product of any environmental influence, as they were simply copies of their caretakers' gestures, but that they were "resilient". These authors define "resilience" as a capacity of a child to invent some properties of language without any formal language input.

There are limitations in systems of gestures, such as those described by GM\&M (1984). They claim that "linguistic input is less important to the development of certain properties of language than to the development of others" (p. 8). Although some properties can be created without a language model, others are more "fragile," as these authors pointed out. They define "as 'fragile' those properties of language that children fail to develop without a supportive linguistic environment" (p. 109). They give examples of studies about children isolated from language models, such as Genie (Curtiss, 1977), who was restrained from linguistic input until the age of 13 and who did not develop her language even after being exposed to good language models. Genie was able to develop the resilient properties of language but not the "fragile" ones. She suffered from the effects of acquiring her first language after the critical period for learning a language.

At this point, we can observe that although many deaf children do not have good language models, some of them have shown the ability to construct their own language system, such as the gesture systems invented by DCHP in GM\&M's study. What are the reasons that some children can create language, while others under the same conditions cannot do the same? Should one claim that an environment which allows more interaction enhances language acquisition?

\footnotetext{
${ }^{1}$ I define the gestures or the home signs the deaf children produce as opposed to signs, which are conventionalized items produced in a sign language. These items are used only with family and close friends, and sometimes people do not understand their intended meaning, contrasting to signs in a sign language, which have a conventional meaning that is shared in the deaf community.
} 


\section{Value of interaction FoR L1 acquisition}

Children need to develop their social skills through language interactions in order to develop their logic. Vygotsky (2000) claims that the direction of thinking is from the social to the individual, not from the individual to the social. Children with no access to a language form that makes it possible to interact with other individuals will have an unsettled intellectual growth.

Snow (1989, p. 83) argues that "no one denies that social interaction is a prerequisite to normal development in language as in other domains". As the interaction of an adult with a language-learning child differs in many ways from adult-adult interaction, she points out that there are some special characteristics of child-directed speech (CDS) that could facilitate language acquisition. In particular, CDS simplifies and clarifies the language in ways that might make it easier for the child to process the information.

Several studies confirm that deaf parents alter their signs when talking to their infants, much like hearing parents do. Emmorey (2002) notes the systematic change in the form of language that adults use with infants appears to be a robust universal language that is not limited to speech. She cites some studies which have shown that CDS in sign language aims to attract the attention of the baby - the signs have longer duration and more repetitions, and the mothers manage to angle their signs to make them more visible to their infants. In this mother-baby interaction, the child acquires not only the language properties, but also discourse patterns, such as turn-taking.

Thus, the normal development of a child depends on the successful interactions she will experience in the family, in the community, and with friends. For deaf children, this discursive interaction is possible if mediated by a language they can access, such as a sign language. Isolated children, as seen in those studied by GM\&M (1984), will not be able to have a discursive interaction if they do not have a partner, even if they were able to create their own language. Consequently, it is impossible for any child to develop language without an interlocutor.

In GM\&M's (1984) study, the parents communicated in gestures with their children, though they rarely shared gestures for the same intended meaning. Despite the fact that the parents' option was to raise their children with the aid of a spoken language, their communication skills consisted of constantly of pointing to objects in the shared environment. Their gestures were also iconic, as were their children's signs, although not identical in form. 
There was communication between parent and child, in such a way that, although it was not perfect, the child had an interlocutor that he/she could understand. As the parents in GM\&M's study were not "proficient" in the children's gesture systems, it did not matter if the interlocutor was an adult or even another child, since both were able to comprehend the meaning through interaction.

\section{Studies on twin language development}

Twins are a good case for increased interaction, since they have an interactive partner from birth. Studies about language development in twins suggest that most young twins have shown inferior development in their communication skills when compared to single children (Deutsch et al, 2001; McMahon \& Dodd, 1997; Gaines \& Helpern-Felsher, 1995; among others). McMahon \& Dodd (1997) claim that both twins and triplets presented delayed phonological development when compared to singletons. Many reasons are involved in this language delay, some of which include: caretakers of twins have many more tasks to do and much less time to interact with them, whereas parents usually treat the twins as a unit in terms of communicative behavior. Moreover, twins - mostly identical twins

- have less stimulus to learn to speak, as they have sufficient understanding of each other through nonverbal communication. Twins, on average, also have a slightly lower verbal intelligence than singletons (Deutsch et al, 2001; Mogford, 1993).

One important point in the family's interactional pattern is that there is a considerable tendency in the mothers of twins to speak to them less and to use utterances of lesser complexity than mothers of singletons. Twins also proved to have fewer and shorter individual conversations with parents than did singletons.

Twins often develop their own language, which is said to complicate and retard language acquisition (McMahon \& Dodd, 1997; Mogford, 1993). Schave and Cirielo (1983) describe a study in which 20 sets of identical twins and 20 sets of fraternal twins were interviewed (all were adults from urban areas in the US). Their study described special languages several twins had developed for fantasy play activities, which were set apart from their verbal communication with their family or friends. Some of them remembered being able to create their own language at about four to five years old. Many reported an ability to communicate nonverbally as children and as adults. Some described that their nonverbal communication was 
based on an invented sign language together with a specific body language.

Zazzo (1978) sees the twins' secret language, or "cryptophasia," as occurring in a period prior to the acquisition of a socialized language in twins. Zazzo suggests that twins have difficulties in separating their identities and need to establish a communication with each other. Consequently, they develop their own system of communication, using one another as models.

Some studies can be found in the literature on deaf and hearing twins; however, to the best of my knowledge, no studies have been conducted with a pair of deaf twins. The three studies that will be reviewed here focus on deaf and hearing twins, raised in environments that involve the use of any kind of sign language. One factor to be considered is that one of the children in each pair is a hearing child, and it is not well-known if this differential hearing status affects the twin-twin relationship.

Gaines \& Helpern-Felsher (1995) observed the development of a pair of deaf and hearing monozygotic twins of hearing parents from 13 months to 36 months of age. The twins' teenage older sister spent a good deal of time interacting with them and had a good vocabulary in Signed English, as stated by the authors; however, not all family members were able to communicate effectively with the twins. The twins' communication with each other was quite rare; instead, while being observed they tended to communicate with the adults who were present in the environment. The hearing twin learned and used sign language, but she preferred oral language rather than signs when communicating with hearing adults. The deaf twin, however, preferred gestures and signs. She rarely used both signs and vocal language concurrently and frequently imitated others' communication rather than using spontaneous language. The authors suggested the fact that both twins rarely communicated with each other, which consequently prevented them from creating their own secret language.

Another study also focused on the development of vocal and signed communication of a pair of hearing and deaf twins, both children of deaf parents (Gaustad, 1995). Their language development was followed from 16 to 24 months of age. Both parents acquired American Sign Language (ASL) late, but the mother's preferred language was ASL, while the father used both ASL and spoken English. An older sister, also deaf, was said to acquire ASL after 4 years of age, which seems strange in a signing environment. Both children interacted with other adults besides their parents. Gaustad found that both twins depended greatly on signed communication. 
Very few interactions were observed between the twins. Although both predominantly signed-only, the hearing twin also attempted to speak. It was observed that, by age two, the twins were producing fewer multi-unit utterances than expected. She points out that the volume of parent-child communication seemed low, which may have affected both twins. The issue of the environment seems problematic in that a four-year old child (the older deaf sister) would not normally acquire a sign language in a signing environment under normal conditions.

Siple and Akamatsu (1991) also followed the language development of a pair of fraternal twins. In their study, the female child could hear, while the male child was deaf, but their deaf parents decided the children should learn ASL as their native language; therefore, both children were exposed to ASL. The hearing child had access to spoken language input from birth through TV and auditory tapes, but this kind of exposure did not stimulate this child's production of spoken language. As the linguistic environment consisted of a sign language, the twins had the opportunity to develop a close relationship and a private language, but they did not, just as in the former two cases.

Siple and Akamatsu (1991) concluded that the pair of twins they studied was not delayed in their language development, and, despite their different hearing status, both children showed similar linguistic development. The acquisition of signs showed a gradual expansion from 12 to 16 months of age, but at 17 months their vocabulary was consistent with the findings from sign language acquisition in singletons. No secret language was observed between the twins during the first years.

The three studies reviewed regarding deaf and hearing twins did not present a true 'twin situation', since neither of the twin dyads contained two deaf twins. Consequently, no pair presented an environment favorable to the emergence of an invented language. The interactive environment varied from a blend of signs and spoken language (Signed English), to ASL and spoken language, to ASL only. Even in Siple and Akamatsu's (1991) study, where the environment provided the same language conditions found in most of the hearing twin studies, the 'twin situation' does not seem to have emerged. A 'true twin situation' is assumed to be an environment in which twins are born, raised, and share the same experiences of the environment. Plenty of opportunities to interact with each other should supposedly arise within this environment, which should in turn make the emergence of an invented language possible. 
From the reviewed literature, it was seen that deaf children exposed to an accessible language develop normally, while deaf children without a language model appear to experience difficulty. Deaf children were shown to create a language within family interactions, comprehending meaning from gestures, even though they did not share the same code with their partner. The literature also showed that some twins create a secret language, as a consequence of the "twin situation," given their need to interact with each other. As no studies of two deaf twins could be found in the literature, all of the predictions formulated by this study are based on deaf and hearing twin siblings. What can be said about deaf twins of hearing parents who have the same problems raised by the "twin situation" and with the additional factor that neither has access to the language used in their environments? Could it be that with two deaf twins in a hearing family, the twin interaction would give rise to a language from the "nonverbal signals in which meanings are shared?"

The specific research questions this paper intends to address are:

1. Does interaction in the absence of a language model give rise to a communication system between deaf twins?

2. Is it possible that the use of a primitive language, such as a twins' secret language, make deaf twins' performance appear typical when they are exposed to a model?

The answers to these questions may lead to a better understanding of the role of interaction in the acquisition of a sign language. It is my intention to present evidence that even poor or weak signs or gestural input can help children construct their language with the aid of a constant interactional partner.

\section{Methodology}

\subsection{Subjects}

Five deaf children participated in this study. One was a DCDP, while and the other four were DCHP. Two DCHP are identical twins ("TW1" and "TW2") and the other two are non-related children ("HP1" and "HP2") (Summarized in Table 1). Their ages ranged from 7:1 to 7:11, with a mean age of 7:5. The age at which DCHP children had their first contact with Libras at school varied from 4:0 to 5:11 years, with a mean age of 4:10 years. 
None of the DCHP had contact with Libras before they entered school. None of the hearing parents know how to use sign language well, although the three hearing mothers were taking Libras classes at school with a deaf sign language teacher. The DCDP had had contact with Libras from birth, given that her deaf parents are active in the deaf community and have many deaf relatives and friends. Despite this signing environment, her parents enrolled her in a daycare center for hearing children when she was 1 year of age, which is reasonable, since there was no other option in the region for deaf children. Later, they enrolled her in an oral school for the deaf when she was 3 years of age.

All of the children were from poor families. They all had at least one older brother or sister, all of whom could hear, except DCDP, who had a younger sister who was also Deaf. HP2, DCDP, and the twins lived with both parents, but only the fathers worked. HP1's father died about one year before the data was collected. HP1 lived with his mother and older brothers.

\subsection{School Environment}

The school the DCHPs attend is a private clinic-school that receives funding from the state for children with special needs - mostly deaf, but some with other anomalies other than hearing loss. Children attend classes for four hours a day, five days a week. Most school personnel were encouraged to take Libras classes in order to communicate with the children, since the school followed a Total Communication Program. Most of the staff uses signs and speech simultaneously, including a deaf teacher, the only deaf adult in the school.

There are no adult native signers at the school, but the most proficient signer is the deaf teacher, who acquired Libras in adulthood (she has been signing for more than 40 years); there is one hearing Libras interpreter, who was also a teacher, and another hearing teacher, who was considered a good signer. The other professionals were not skilled, but they also used signs to communicate. The children in this study only had contact with one of the proficient signers - the deaf teacher - who used to give them weekly lessons. Their regular teachers were not proficient signers.

The oral school that DCDP attends is a private religious school that has followed the oral approach for more than fifty years. DCDP attends school for a period of four hours a day, five days a week. Despite the school administration's prohibition of signs, some of the teachers sometimes used signs to teach, but there was no known proficient teacher in school at the time of the study. Recently, it was said that the school has begun to accept 
the use of sign language in the classrooms, but at the time of our recordings signing was allowed only during non-classroom time.

TABLE 1

Summary of the subjects

\begin{tabular}{|c|c|c|c|c|c|}
\hline Child & DCDP & HP1 & HP2 & $\begin{array}{c}\text { TW1 }\left(1^{\text {st }}\right. \\
\text { born twin })\end{array}$ & $\begin{array}{c}\text { TW2 }\left(2^{\text {nd }}\right. \\
\text { born twin }\end{array}$ \\
\hline Gender & Female & Male & Female & Male & Male \\
\hline Parenthood & DCDP & \multicolumn{4}{|c|}{ DCHP } \\
\hline Age & $7: 3$ yrs & $7: 1$ yrs & $7: 4$ yrs & $7: 11$ yrs & $7: 11$ yrs \\
\hline $\begin{array}{c}\text { Age at } \\
\text { the start of } \\
\text { school }\end{array}$ & $\begin{array}{c}1: 0 \text { (school } \\
\text { for hearing } \\
\text { children) }\end{array}$ & $\begin{array}{c}4: 0 \text { (school } \\
\text { for the } \\
\text { deaf) }\end{array}$ & $\begin{array}{c}5: 11 \text { (school } \\
\text { for the deaf) }\end{array}$ & $\begin{array}{c}5: 2 \text { (school } \\
\text { for the deaf })\end{array}$ & $\begin{array}{c}5: 2(\text { school } \\
\text { for the } \\
\text { deaf })\end{array}$ \\
\hline $\begin{array}{c}\text { Time of } \\
\text { signing }\end{array}$ & Birth & $3: 1$ yrs & $1: 5$ yrs & $2: 9$ yrs & $2: 9$ yrs \\
\hline $\begin{array}{c}\text { Teachers' } \\
\text { proficiency in } \\
\text { signs }\end{array}$ & $\begin{array}{c}\text { No signs at } \\
\text { school }\end{array}$ & \multicolumn{5}{|c|}{ Not skilled } \\
\hline $\begin{array}{c}\text { Parents' } \\
\text { proficiency in } \\
\text { signs }\end{array}$ & $\begin{array}{c}\text { Deaf parents } \\
\text { Libras users }\end{array}$ & \multicolumn{5}{|c|}{ No proficiency } \\
\hline Observation & \multicolumn{5}{|c|}{ No other impairment was observed } \\
\hline
\end{tabular}

\subsection{Description of the test}

This task is from a research study on the Theory of Mind development in deaf children who are acquiring ASL (De Villiers et al., 2003; Schick, de Villiers, de Villiers \& Hoffmeister, 2002; among others). This task is referred to as "The Cat Protocol." 2 This is a task of language interaction between two deaf adults and the deaf subjects. Toy animals are used to elicit language comprehension and language production. The interaction is designed to elicit specific language structures containing mental verbs. The task contains a series of vignettes that are acted out by the examiner, an accomplice, and the child. The accomplice is dressed as a cat. The child is told that the "cat" has never been to school and needs help in understanding what to do. The child is then asked to function as a "relay" between the examiner and the

\footnotetext{
${ }^{2}$ The cat protocol has been adapted from Crain (1993).
} 
accomplice (the cat). The vignettes vary in degrees of difficulty, ranging from easy (e.g., "two baby toy lions enter the scene jumping and rolling over each other") to more complex (e.g., "a rhinoceros, a gorilla and an elephant are licking/drinking water in a lake. Suddenly a lion appears on the other side of the lake and starts licking/drinking water too. The other animals escape quickly, afraid of the lion, which remains drinking water alone"). The intent of these vignettes is to elicit from the child structures that present what the animals are thinking. For example, the lion thinks the rhino will hurt the baby.

Examiners: The examiners were two deaf adults skilled in Libras - one (called Examiner) managed the toys and interacted directly with the child, telling stories, asking questions (a), and resolving doubts (b). The examples ${ }^{3}$ (a) to (c) are taken from the data to represent different interactions:

(a) Types of Examiner's questions: "What are the baby lions doing?"
or
"Ask the cat how he thinks the lion is
feeling now."

(b) Type of a child's doubts:

Child: "SIGN WORRY UNDERSTAND NOT"-meaning: $I$ did not understand the sign "WORRY". - Then the Examiner explains the meaning of the sign to the child.

The other examiner, dressed as a cat, pretended not to pay attention and had to answer questions asked by the child - the cat was instructed to give mostly wrong answers (c), and make comments that did not fit what was happening in the vignettes.

\footnotetext{
${ }^{3}$ The following conventions will be used in describing examples of propositions of the examiners and subjects: (1) “UPPER CASE LETTERS" represent a signed proposition - each word corresponds to one sign, TWO-WORDS hyphenated represent only one sign; (2) "lower case letters" represent the English translation of a proposition; and (3) "POINT-elephant" represents the pointing in upper case and the direction of pointing in lower case letters.
} 
(c) Type of Cat's wrong answers:

Examiner: "Ask the cat what the baby

lions are doing."

Child: "POINT-lions WHAT?"

Cat: "POINT-lions FIGHT"- correct answer: "POINT-lions PLAY"

The examiner always asked questions about what was happening - the child's comprehension of the story (e.g., "what is the baby doing"), the intent of the toy animals (e.g., "why didn't the baby elephant follow its mom?"), the child's comprehension of the cat's understanding of the story (e.g., "what did the cat say that the baby elephant was doing?"), and if the cat's answers were right or wrong (e.g., "is the cat right?").

The task was administered to all DCHP at their school in a separate room with the two examiners and the researcher, who was recording in video. The children were tested individually. The DCDP was tested at her grandmother's home, with her parents' agreement, since she attends an oral school that did not agree to collaborate in the research.

\subsection{Coding and Analysis}

The data was recorded using a Panasonic camcorder. The videos were transcribed by the author, who has been a Libras interpreter for 20 years.

Each child was recorded for about 15 minutes during the task. Each session yielded the following minutes of actual interaction with each child. The average amount of actual time of responses was 6:19 minutes:

- DCDP 05:22 minutes

- HP1 07:18 minutes

- HP2 05:26 minutes

- TW1 08:20 minutes

- TW2 05:08 minutes

The coding was divided into three categories: "Interaction: number of lexical items produced," "Lexical items by similarity in form to Libras," and "Interaction patterns," which are detailed below. 


\subsubsection{Interaction: Number of lexical items produced}

The first analysis counted the lexical items (signs) as compared to non-lexical items (gestures). The objective of this analysis was to compare the similarities and differences among the children at the word level in the discourse. During interactions, a child can sometimes communicate her feelings and desires by pointing, using isolated gestures or head movements, or by using signs, whether isolated or combined with other signals. As the child acquires competence in using language, lexical items replace non-lexical items, though these items are not always similar to the adult pattern. When a child uses Sign Language sentences, she can communicate her feelings more clearly than another child who uses only isolated gestures, head movements, and isolated pointing.

A measure of meaning was defined by counting the number of lexical items produced in the interaction as compared to the total number of gestures. In this analysis, signs produced by the use of hands or body, as well as pointing (which has a similar grammatical function to pronouns), were considered lexical items. Head movements or gestures, such as facial expressions alone, were considered in the category of gestures.

\subsubsection{Lexical items by similarity in form to Libras}

The second type of analysis compared the similarity of each child's lexical productions to lexical forms in Libras. The similarity to Libras vocabulary was analyzed in order to verify the possibility of signs that might be created by the twins to communicate. If they created a private language similar to that of hearing twins, at least some lexical items should be different than the ones used in Libras. This was a distinct possibility, given that these twins had only 2:9 years of language exposure and that most of their models were not skilled in Libras.

This analysis was coded according to the citation form of lexical items used during the interactions. The lexical items that showed any variation in form - in handshape, point of articulation, or movement - were listed and checked according to a Libras dictionary (Dicionário de Libras Ilustrado, 2002).

In addition, the following procedure was used to check the lexical items with a near-native Libras user if the sign was not in the dictionary:

1. The video of all children tested was shown, stopping the video and asking what each child intended to say. The Deaf person's response indicated 
whether he/she understood the children - he/she answered all questions using Libras.

2. Specific scenes were selected and viewed as many times as needed (using slow motion if necessary), asking the intended meaning of unknown or odd signs.

There were only a few items from the twins' production for which the intended meaning could not be detected. These items were set apart and were not included in the analysis.

The percentage of the number of occurrences of each item was taken according to the total number of lexical items produced during each child's interaction. Each instance of a sign (token) was counted, and the proportion was taken according to the total number of tokens produced by each child.

\subsubsection{Interaction Patterns}

This analysis was conducted on the discourse interaction with the two experimenters. The first point observed in the interaction patterns was the turns taken during the interaction. The objective was to determine if any difference could be observed in the responses when the child interacted with one examiner or the other. The second point observed was their type of responses. The level of complexity of their responses in the interaction needed to be evaluated, since it showed the child's level of language knowledge. The third and final point observed in their interaction was the percentage of correctness of the responses in comparison to non-responses. The following is a detailed explanation of each category in the interaction patterns.

\section{a. Turn-taking during the test}

The interactions were coded according to the number of turns taken during the test. Turn-taking counts were catalogued according to who directed the "speech" to which interlocutor - 1) "E1 to child" (E1 is the Examiner who interacted directly with the child); 2) "E2 to child" (E2 is the second examiner, who was characterized as a cat); 3 ) "child to E1"; or 4) "child to E2". The number of non-responses was also coded.

A turn was counted when the interlocutor stopped signing and looked to the receiver. When the receiver acknowledged the contact and turned his/ her eyes away from the interlocutor, the turn was concluded. 


\section{b. Types of responses}

The interaction was then coded according to the types of responses given by each child in the dialog. Each response corresponds to a "communicative unit." A communicative unit can be a large number of sentences in response to a stimulus, a short sentence, or a meaningful question, as well as to head movements, incomplete responses, isolated gestures, isolated pointing to any referential location, and/or non-comprehensible answers. Communicative units were coded as "yes/no" answers, "expanded responses," or "other" responses (gestures, incomplete statements, nonsense answers, isolated words, or isolated pointing). The non-responses were also coded.

TABLE 2

Summary of Interaction Patterns

\begin{tabular}{|l|l|}
\hline Types of responses & \multicolumn{1}{|c|}{ Types of communicative units } \\
\hline "yes/no" answers & 1) head nod "YES" or head shake "NO" \\
\hline & $\begin{array}{l}\text { 2) a short sentence (e.g., "POINT-lion ANGRY" - translation: } \\
\text { The lion is angry) }\end{array}$ \\
\cline { 2 - 3 } 3) a large number of sentences (e.g., "POINT-baby SEE RHINO \\
WATER / POINT-rhino WATER / POINT-mom POINT- \\
rhino FIGHT / POINT-baby HIDE / DANGER HIDE / (I) \\
UNDERSTAND WHAT" - translation: The baby (lion) sees \\
the rhino licking water. Mom (lion) and the rhino (might) fight, \\
(so), the baby hides (because) it is dangerous. I understand what \\
(has happened there))
\end{tabular}




\section{c. Correctness of responses in turn-takings}

It was considered a successful response if a child responded correctly, regardless of whether she gave a complete statement or a head movement. A "wrong answer" was considered when the child's answer did not fit with the question presented. An example of an incorrect sequence is as follows:

Examiner: "ASK-cat DO++ WHAT"-"Ask the cat what (the lions) are doing."

Child: "QUESTION DO++WHAT POINT-lions QUESTION""What are the lions doing?"

Cat: "FIGHT POINT-lions"- The lions are fighting" (when the Examiner's presentation showed clearly that the lions were playing)

Examiner: "RIGHT POINT-cat?" - "Is the cat right?"

Child: "HEAD-NOD" - "Yes"

Sometimes a child started answering incorrectly, but then retracted and answered correctly, amending her answer. In this case, the answer was considered correct. Other times the child answered " $M A Y B E$ " when a "RIGHT" or "WRONG" answer was expected. In this case, the answer was considered incorrect. The objective of the analysis was to determine whether the twins' performance in Libras appeared typical to DCDP or if it would be similar to the HP's.

The correct responses were checked according to the turn-taking. Each time the child responded appropriately was counted as a correct turn.

\section{Results}

The average of the length of time of the children's responses was 6:19 minutes. There is no correlation of the length of time of the children's responses to the amount of information provided in their responses, nor to successful responses. For example, DCDP, who is the Libras language model, spent 5:22 minutes in her responses (which were successful most of the time), while HP2 spent 5:26 minutes in her responses, but many of her responses were unsuccessful. On the other hand, HP1 and TW 1 spent more time than DCDP in their responses (7:18 and 8:20 minutes, respectively), 
while TW2 spent 5:08 minutes, but the amount of information provided by HP1's responses was not similar to the twins. Consequently, the time spent in the responses does not correlate with the amount of information provided, which can be observed in the results presented in the sections below.

\subsection{Number of lexical items produced}

The twins' production of lexical and non-lexical items was comparable to DCDP's, which can be seen in Chart 1.1. This result shows that the twins were able to produce meaningful units, using lexical items with a performance similar to a child who has had contact with Libras from birth. By contrast, the results for both HP children showed that they were able to produce meaning using lexical items, but they were not able to perform at the level of both twins and the DCDP. As shown in Chart 1, only $80 \%$ and $73 \%$ of the total number of items produced by HP1 and HP2, respectively, were meaningful lexical items. In contrast, over $90 \%$ of the items produced by DCDP and the twins were meaningful lexical items.

\section{CHART 1}

Proportion of lexical versus non-lexical items produced (\%)

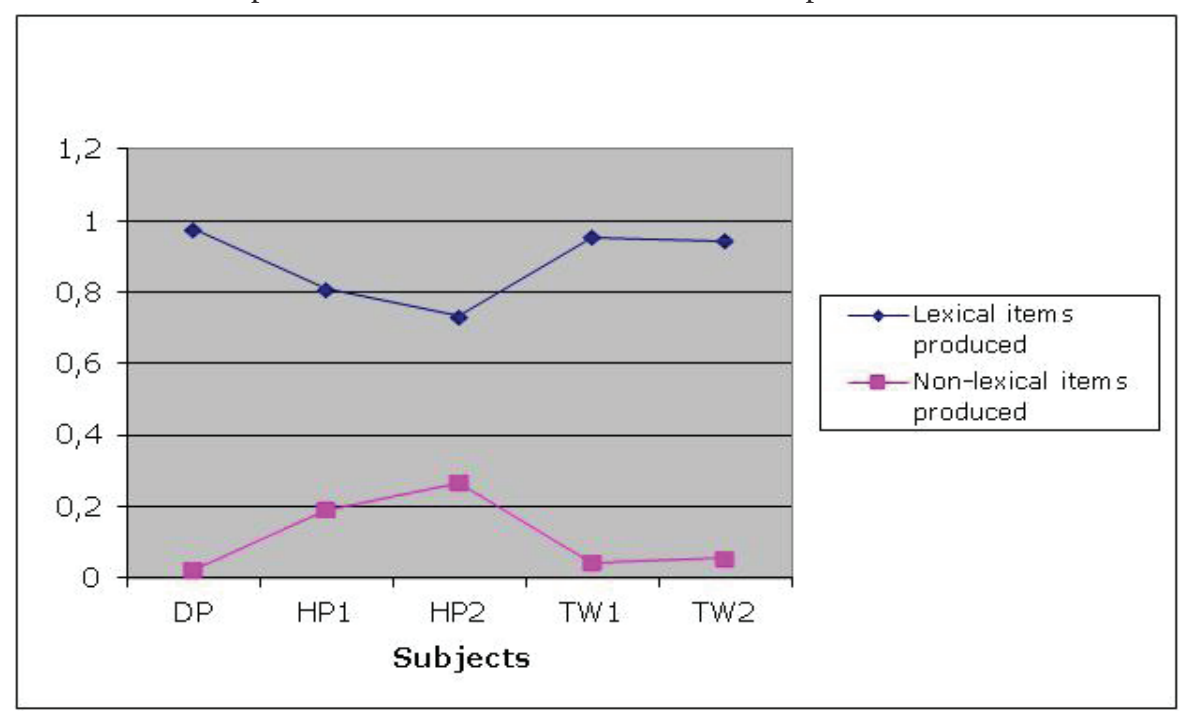


The expressiveness of this difference can be seen when the raw scores are presented. Table 3 contains the raw numbers of lexical and non-lexical items produced.

TABLE 3

Raw number of lexical items produced (tokens)

\begin{tabular}{|c|c|c|c|}
\hline Subjects & Lexical items produced & Non-lexical items produced & Total \\
\hline DP & 168 & 4 & 172 \\
\hline HP1 & $\mathbf{5 1}$ & 12 & 63 \\
\hline HP2 & $\mathbf{3 3}$ & 12 & 45 \\
\hline TW1 & 172 & 8 & 180 \\
\hline TW2 & 116 & 7 & 123 \\
\hline
\end{tabular}

HP1 produced a total number of 51 lexical items, and HP2 produced 33 lexical items, while the other three children produced an average of 152 items. If the two HP subjects are compared to DCDP, who is the Libras language model, HP1 produced about $30 \%$ of DCDP's items, and HP2 less than $20 \%$ of DCDP's lexical items. This result clearly shows that the twins' language production is very close to DCDP, yet far from HP1 and HP2, in the number of lexical items produced.

\subsection{Lexical items by similarity in form to Libras}

This semantic-morphological analysis verified the production of lexical items according to Libras patterns. Chart 2 shows the results obtained when comparing all of the children's lexical items with a Libras pattern. In the production of lexical items, only DP produced all items in accordance with Libras (according to a Libras dictionary in CD-ROM, the author's, and one near-native deaf user of Libras evaluations). The other children presented some variation: HP1 1.9\%, HP2 3.0\%, TW1 5.7\%, and TW2 7.2\%. Only one instance of a different sign was counted (one type), even though it may have appeared many times during interaction (many tokens). 
CHART 2

Pattern of production of lexical items according to Libras (\%)

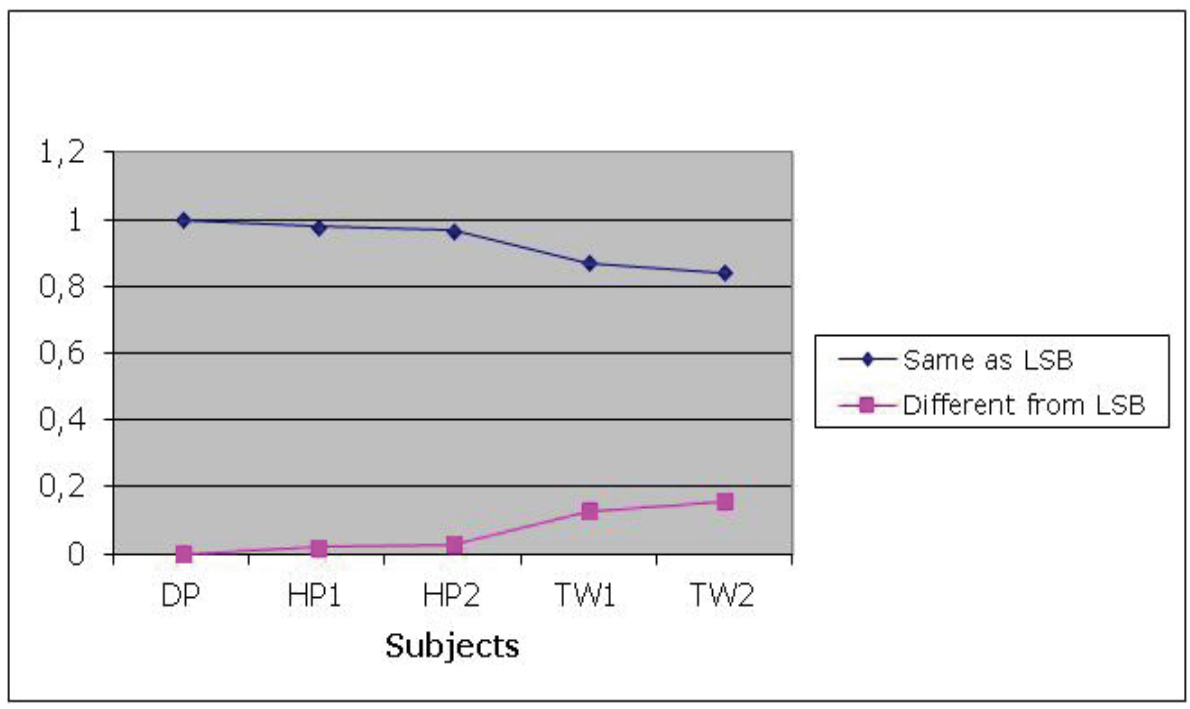

In Section 5.4.2, it was explained how Libras lexical items were counted. In Chart 2 the pattern of the production of lexical items is presented for each child. The twins appeared to create their own signs. For example, TW2's sign for LICK [B change into bent-B in front of the mouth, palm up] is similar to the Libras's sign for EAT, with a small difference in the mouth, which opens and closes in the final handshape of EAT but remains open in the final handshape of LICK, exposing the tongue.

Other signs that the twins performed differently from Libras were COME (one or both hands open [B] palm-up, moving many times from outside to inside, near the chest), and GO (using [B] handshape palm-down, with movements from inside to outside). Both signs are similar to gestures ${ }^{4}$ used in the hearing community.

The twins produced the verbs BEAT and BE-LATE differently from the standard Libras forms. BEAT used the same handshape [S], place of articulation, and initial movement of the Libras sign, but the final movement,

\footnotetext{
${ }^{4}$ The use of the twins gestures COME and GO, as well as the pointing gestures that appeared in all participants' production, raises an interesting question about the similarity of these gestures to those used by hearing people. However, this will not be discussed here, because it is beyond the main purpose of this paper. It will be discussed in further research.
} 
instead of hitting the other hand in the palm of [B], rotated (twisted at the wrist) while in contact with the base hand, such as "mashing" something. BE-LATE is produced in Libras using the [L] handshape touching with the thumb the palm of the other hand in $[\mathrm{B}]$ and rotating the wrist of the $[\mathrm{L}]$ hand. Both twins produced BE-LATE with an open hand [5] instead of [L], with the same movement. This version is related to the sign in Libras with the meaning of STEAL, which is not the same.

\section{TABLE 4}

Signs in Libras $\mathrm{x}$ Signs produced by the twins

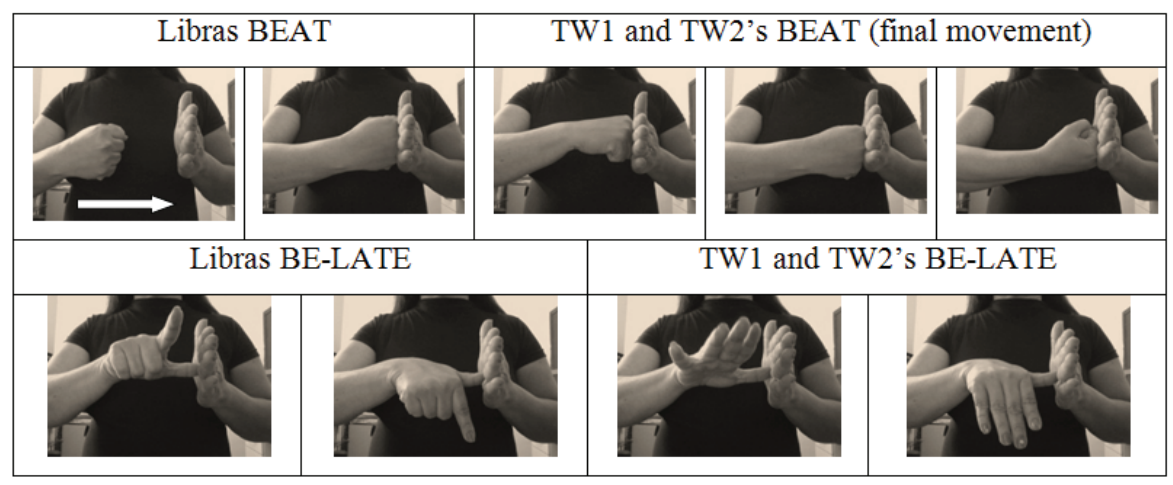

The main differences from the Libras signs consisted primarily of handshape differences: $43.2 \%$ of deviations were handshapes, $32.4 \%$ were handshapes and movements together, and $13 \%$ were movements only. This pattern of deviation apparently did not obscure the message, as the examiners, the author, and the deaf consultant were able to understand the modified signs used by the children.

\subsection{Interaction Patterns}

\section{a. Responses to the instructions (in turn-takings)}

The number of successful turns during the interaction was the first analysis conducted to examine interaction patterns. All children, except HP2, showed a typical pattern of interaction. All of them had successful interactions with both examiners, but HP2's level of interaction with Examiner 2 was very low - she mostly limited herself to looking at the cat and looking back at the Examiner, when she seemed not to know what she had to 
do. It is possible to note that only HP2 encountered substantial difficulties in following the instructions correctly.

\section{b. Type of responses}

The type of response produced by each child during the test was analyzed in order to further examine the interactions. Chart 3 summarizes the types of responses obtained. Examples of types of responses are in Table 2 , section 5.4.3(b).

Complexity of responses to questions (\%)

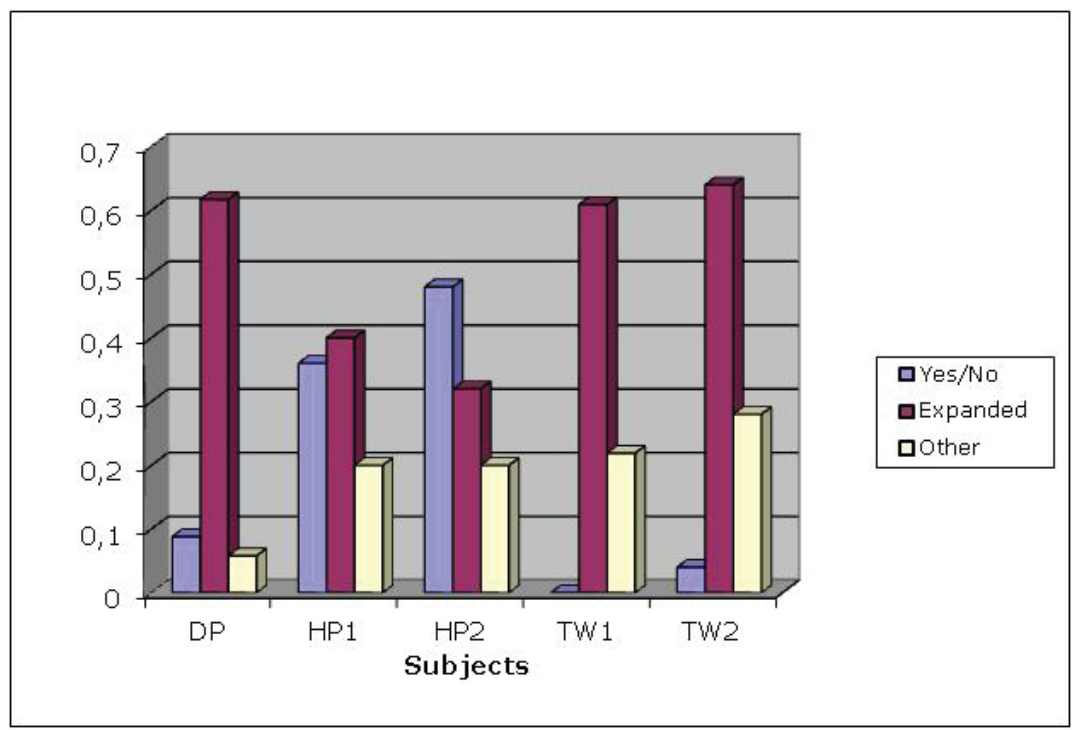

Note that the twins were equal to DCDP in Expanded responses (about $60 \%$ each), while the DCHP had only 40\% (HP1) and 32\% (HP2) of such responses. On the other hand, both HP presented a greater amount of yes/ no answers (HP1 36\% and HP2 48\%), while DCDP presented only 8.8\% and TW2 4\%. The twins, HP1, and HP2 presented many occurrences of other responses (gestures, incomplete responses, isolated words, pointing, and nonsense answers) - more than $20 \%$ each, while DCDP presented only a few of those (5.8\%). Each response consists of a communicative unit. In some instances, a communicative unit consisted of an isolated gesture of misunderstanding (coded as "other"), whereas in other occurrences, it consisted of a sentence or sequence of sentences in a short story (coded as 
"expanded"). This analysis shows both the percentage and complexity of the responses obtained from all the children.

These results again showed that the twins' performance was similar to that of DCDP during their interaction in the test; however, an examination of how many of these answers were correct is necessary to lead to the understanding of the quality of the interactions. The quality of all children's responses is shown in the final analysis.

\section{c. Correctness of responses in turn-takings}

The final analysis conducted was the number of turns in which the children responded correctly. Chart 4 indicates the percentage of correct responses in the interaction. In this analysis, a yes/no answer was considered comparable to a complete statement or a gesture (other responses).

CHART 4

Percentage of correctness in the interaction

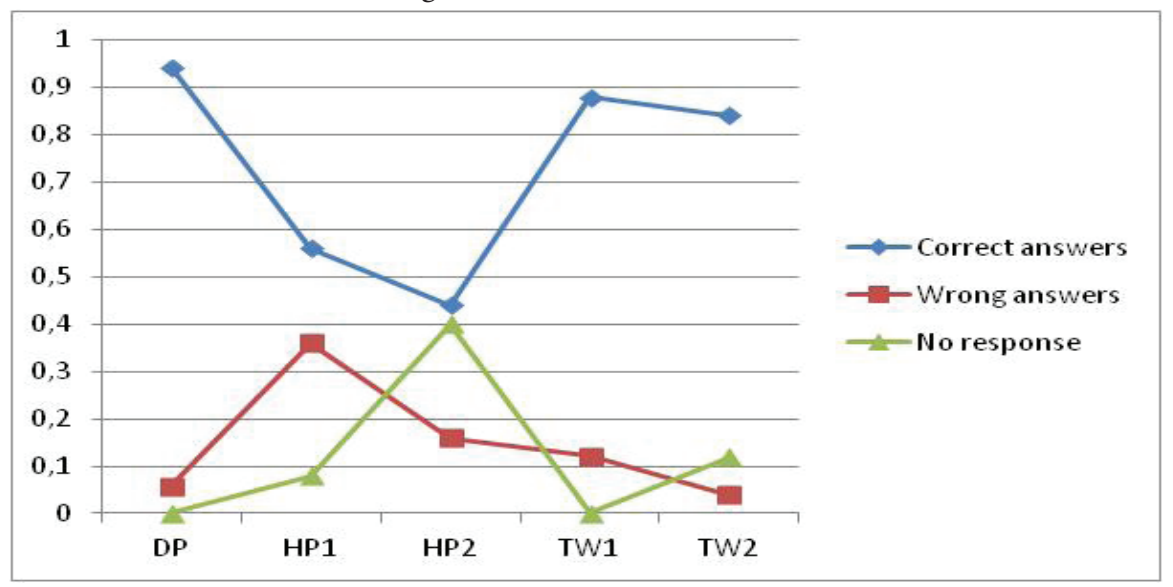

Chart 4 shows that the twins performed at or near the upper level in their interaction with deaf adults in the test. The twins' performance in their interaction patterns is clearly similar to DCDP's, which indicates that their language ability makes it possible for them to successfully interact with deaf adults, understanding them and making themselves understood. For both HPs, the number of correct responses obtained by them seems to be very low in comparison to DCDP and the twins. For example HP2, whose level of non-responses was very high, demonstrated very poor command of the interaction process. 


\section{Discussion}

The results obtained in the responses of all children clearly showed that the DCDP who had exposure to Libras from birth was able to acquire language in a natural and timely process.

Most of the results obtained in the children's interaction task with the deaf adults demonstrated that the twins' results were very similar to those of DCDP and superior to both HPs. This fact reinforces our previous hypothesis that both twins would perform similarly to DCDP, despite the fact that they did not have opportunities for language interactions from birth in the same way that DCDP had.

The twins were able to perform in the language interaction task in a similar manner as native speakers only 3 years after they had had their first contact with Libras. This was accomplished despite the wide range of variables that might have negatively influenced their language development, such as hearing non-signing parents, a relatively late entrance to school consequently having late access to Libras, non-proficient Libras teachers at school, and the non-existence of an educational program to develop sign language skills, among others.

The twins were also involved in a typical "twin situation," which was said to be unfavorable to normal language development in hearing twins who had been exposed to structured language models from birth (Zazzo, 1978; Mogford, 1993).

Twin studies have shown that the twins usually receive less attention and engage in fewer language interactions with caretakers when compared to the same language behaviors found in singletons. It seems that hearing twins may well have communication problems, mainly because their ability to communicate and interact with each other in a private language reduces opportunities and motivation to communicate with individuals other than the twin pair (Mogford, 1993). Hearing twins reduce their social interactions by using their "own language," and appear to limit their language development to each other, although they have the potential of improved interaction with other language models in their environment, unlike deaf children. Deaf twins who do not have access to a structured language from birth also have the potential to create their own language. This process may not isolate them, or even reduce their social interactions, but it may allow them access to the possibilities of the outside world. Deaf twins of hearing parents may present a different case from the twins in Siple 
and Akamatsu's (1991) study, which revealed language opportunities that were similar to DCDP's.

Both twins in this study presented results that were similar to DCDP in the production of meaning, as well as in their successful interaction with both examiners. They performed similarly to DCDP in the quantity of information provided (e.g., similar numbers of lexical items), in quantity and quality of interaction with the examiners (e.g., fewer yes/no answers, more complete statements), and produced correct responses similar to those formulated by DCDP. The twins showed the capacity to begin a conversation and maintain a dialog that was comprehensible. The accuracy of their responses provided the foundation to perform at a high level, and they accomplished all this without access to adult language models.

This raises the question as to why these twins were able to perform much like a native signer, especially when one would expect their environment to influence their language acquisition negatively.

The results showed that all of the deaf children were able to interact with both deaf experimenters (Chart 3). The primary difference among the children was in the pattern of the interaction in that both twins and DCDP had knowledge of a language at a level that made it possible for them to answer questions, begin a conversation, and explain the content of the stories, while the other two children did not show the same level of fluency in their language skills. Both HP children were able to interact, but they had to use all the tools they had, including head movements, gestures, and nonsense answers, as well as simple and a few embedded sentences. Their vocabulary was limited, suggesting that they have not mastered the language they were invited to use to interact with the deaf adults. HP1 had only $3: 1$, while HP2 had only $1: 5$ years of contact with Libras. In contrast to DCDP, who was exposed to Libras from birth, and had been acquiring it naturally, the DCHPs were behind in the acquisition process. Neither of the HPs had the language level that they needed to communicate in these types of interactions.

In comparison, the twins also had limited contact with Libras, since they entered school 2:9 years before the testing was conducted when they were 7:11 years of age. The twins made use of other language tools, such as gestures, pointing, and head movements; however, they also demonstrated a fluency that is uncommon to late first language learners. They were able not only to understand the test procedure and to respond correctly to what 
they were asked to do, but also to create a scenario from the stimulus they had received and to request clarification when they did not understand the information given; in other words, they had a relatively complete language that helped them communicate efficiently. How did they acquire this language?

The deaf twins developed a form of communication very early on and that appears to have satisfied their communication needs until they came in contact with a conventionalized language, Libras. Their homesigns and gestures appear to have been sufficient for interacting with each other and their mother until they entered school. There, they adapted their "primitive language" to the Libras pattern they encountered and reinternalized their language, a pattern called denativization, as proposed by Andersen (1983). The Nativization hypothesis proposes that when individuals do not have access to language data, they turn to their biological capacity for language and construct their own language according to internal rules (Gee \& Goodhart, 1995). As individuals gain access to data about the language, they modify their original grammar according to the rules of the language to which they are exposed.

The Nativization hypothesis appears to depend on some type of consistent interaction, since the two other DCHPs (HP1 and HP2) did not have access to language data from birth and did not acquire language at the same level as the twins. If the HPs constructed any type of language, it was not strong enough to help them acquire a sign language. It seems that the deaf twins created their own language to communicate with each other. This language was used to socialize with other people in their family environment, and perhaps in other environments, such as at school. The only difference between the twins and the other two DCHPs is that they did not have a consistent partner to interact with, which appears to be the necessary condition for language learning.

This study demonstrates the value of early interaction in language acquisition and development. Even though there was no adult model, the twins derived some type of communication process among themselves. This pattern is similar to GM\&M's (1984) deaf children who developed a gesture system without an adult model but had someone to interact with. In this line of thinking, DCHPs who do not have someone to interact with and engage in the transfer of meaningful information very early on in their lives will not develop the tools needed for social interactions.

The results obtained from the twins' language production in comparison to both DCDP and HP confirm our hypothesis that even poor or weak signed or gestural input can help a child construct language, setting 
up the necessary parameters for communication; however, it is necessary to have a constant interactional partner. It seems that early interaction between deaf twins makes a difference in the extent of their language acquisition and not necessarily in the form of the language.

What is required in the interaction? Interaction requires that at least two people be in contact in an environment that allows mutual communication to occur. Language fluency is desirable but apparently not obligatory in the early years of life, given that some children are able to create language without adult input (as the present and GM\&M's (1984) studies have shown). Even adults are able to create languages; when they are in situations where they do not know the language, they are able to communicate using gestures and/or create pidgins. The twins had this type of environment, as they had a partner to interact with from birth. Thus, the children need to have access to good language models as early as possible so that they can acquire the advanced features of the language.

This study does, however, present some limitations. First, to the best of our knowledge, there is no other known study of deaf twins of hearing parents to compare these results with. The studies reviewed here all featured one deaf and one hearing twin. It seems that the fact that one of the twins was hearing and the other one was deaf blocked the occurrence of a viable created language, as seen in the Libras twin situation. This finding suggests that future research on Deaf twins with hearing parents is needed to observe if the "twin situation" is comparable to the hearing twin studies.

Further study would also benefit from longitudinal studies of twins from the same linguistic environment. This would allow for a comparison to DCDPs, resulting in a wider diversity of information available regarding the phases of their language development.

The results obtained from this study provide a unique perspective into language acquisition and the role of early interaction in language acquisition. It was possible to compare language production results from DCHPs to that of DCDPs. We can now reflect upon the question asked at the beginning of the study, "Is there anything apart from exposure to a comprehensible language model that could allow DCHPs to improve in their language performance?" The results were very clear: it seems that the early interaction between twins does in fact make a difference and that early language interaction is necessary for all deaf children to achieve successful language acquisition and development. 


\section{References}

ANDERSEN, R. A language acquisition interpretation of pidginization and creolization. In: ANDERSEN, R. (Ed.) Pidginization and Creolization as Language Acquisition. Rowley: Newbury House, 1983.

CRAIN, S. Language Acquisition in the Absence of Experience. In: BLOOM, P. (Ed.), Language acquisition: Core readings. Cambridge: MIT Press. 1993. p. 364-409. CURTISS, S. Genie: A psycholinguistic study of a modern day "wild child". New York: Academic Press, 1977.

DEUTSCH, W. A.; WAGNER, R.; BURCHARDT, N.; SCHULZ \& NAKATH, $\mathrm{J}$. Person in the language of singletons, siblings, and twins. In: BOWERMAN, M. \& LEVINSON, S. (eds.) Language acquisition and conceptual development. Cambridge: Cambridge University Press, 2001.

DE VILLIERS P., DE VILLIERS, J., BRODERIC, K., EDDY, N., FRIEDMAN, J., FREEDMA, S., PYERS, J., SCHICK, B., CALDWELL, E., HOFFMEISTER, R. The Language of Mental State Explanations: Conceptual, Semantic and Syntactic Issues in Normal and Delayed Development. Symposium presented at the International Association of Child Language Disorders, Madison, 2003.

DICIONÁRIO de Libras Ilustrado. CD-ROM that provides key information on the use of Brazilian Sign Language (Libras). Sao Paulo: Secretaria de Estado do Governo e Gestão Estratégica, 2002.

EMMOREY, K. Language, Cognition, and the Brain: Insights from Sign Language Research. London: Lawrence Erlbaum Associates, 2002.

GAINES, R. \& HALPERN-FELSHER, B. L. Language Preference and Communication Development of a Hearing and Deaf Twin Pair. American Annals of the Deaf. Vol. 140, issue 1, Columbus, 1995. p. 47-55.

GAUSTAD, M. G. Development of vocal and signed communication in Deaf and hearing twins of Deaf parents. In: STRONG, M. (Ed.) Language Learning and Deafness. $4^{\text {th }}$ ed. Cambridge: Cambridge University Press, 1995.

GEE, J. \& GOODHART, W. American Sign Language and the human biological capacity for language. In: STRONG, M. (Ed.) Language, learning and Deafness. Cambridge: Cambridge University Press, 1995.

GOLDIN-MEADOW, S. \& MYLANDER, C. (GM\&M) Gestural Communication in Deaf Children: the Effects and Noneffects of Parental Input on Early Language Development. Monographs of the Society for Research in Child Development. Vol. 49, issues 3-4, Chicago, 1984. 
HOFFMEISTER, R. A Piece of the Puzzle: ASL and Reading Comprehension in Deaf Children. In: CHAMBERLAIN, C; MORFORD, J. P. \& MAYBERRY, R. I. (Eds.) Language Acquisition by Eye. Mahwah \& London: Lawrence Erlbaum Associates. 2000. p. 143-163.

LILLO-MARTIN, D. Modality Effects and Modularity in Language Acquisition: The Acquisition of American Sign Language. In: RITCHIE, W.C. \& BHATIA, T.K. (Eds.), Handbook of child language acquisition. San Diego: Academic Press. 1999. p. 531-567.

MAYBERRY, R. The importance of childhood to language acquisition: Insights from American Sign Language. In: GOODMAN, J.C. \& NUSBAUM, H.C. (Eds.), The development of speech perception: The transition from speech sounds to words. Cambridge: MIT Press. 1994. p 57-90.

MCMAHON, S. \& DODD, B. A comparison of the expressive communication skills of triplet, twin and singleton children. European Journal of Disorders of Communication. Vol. 32, London: Whurr Publishers, 1997. p. 328-345.

MEIER, R. Language Acquisition by Deaf Children. American Scientist. Vol. 79, issue 1, Jan-Feb, Research Triangle Park, NC: Sigma Xi. 1991. p. 60-70.

MEIER, R. \& NEWPORT, E. Out of the Hands of Babes: on a Possible Sign Advantage in Language acquisition. Language. Vol. 66, issue 1, Washington, DC: LSA. 1990. p. 1-23.

MOGFORD, K. Language development in twins. In: BISHOP, D. \& MOGFORD, K. (Eds.) Language Development in Exceptional Circumstances. Hove (UK) \& Hillsdale (USA): Lawrence Erlbaum Associates, 1993.

MORFORD, J. \& MAYBERRY, R. A Reexamination of "Early Exposure" and Its Implications for Language Acquisition by Eye. In: CHAMBERLAIN, C; MORFORD, J. P. \& MAYBERRY, R. I. (Eds.) Language Acquisition by Eye. Mahwah \& London: Lawrence Erlbaum Associates, 2000. p. 111-127.

NEWPORT, E. \& MEIER, R. The Acquisition of American Sign Language. In D. Slobin (Ed.) The Cross-linguistic Study of Language Acquisition, vol. 1: The Data. Hillsdale: Lawrence Erlbaum Associates. 1985. p. 881-937.

PADDEN, C. \& RAMSEY, C. American Sign Language and Reading Ability in Deaf Children. In: CHAMBERLAIN, C; MORFORD, J. P. \& MAYBERRY, R. I. (Eds.) Language Acquisition by Eye. Mahwah \& London: Lawrence Erlbaum Associates, 2000. p. 165-190.

SHAVE, B. \& CIRIELLO, J. Identity and Intimacy in Twins. New York: Praeger Publishers, 1983. 
SCHICK, B.; DE VILLIERS, J.; DE VILLIERS, P. \& HOFFMEISTER, R. Theory of Mind: Language and Cognition in DeafChildren. Paper presented at The American Speech, Language, and Hearing Association, 2002.

SIPLE, P. \& AKAMATSU, C. T. Emergence of American Sign Language in a set of fraternal twins. In: SIPLE, P. \& FISHER, S.D. (Eds.) Theoretical issues in sign language research. Chicago: University of Chicago Press, 1991.

SNOW, C. E. Understanding Social Interaction and Language Acquisition; Sentences are not Enough. In: BORNSTEIN, M. \& BRUNER, J. (Eds.) Interaction in Human Development. Hillsdale: Lawrence Erlbaum Associates, 1989. p. 83-103. VYGOTSKY, L. Thought and Language. Cambridge: The MIT Press, 2000.

ZAZZO, R. Genesis and peculiarities of the personality of twins. In: NANCE, W.E.; ALLEN, G.; PARISI, P. (Eds.) Twin research: progress in clinical and biological research: psychology and methodology. New York: 1978.

Data de submissão: 28/07/2014. Data de aprovação: 15/09/2014. 